\title{
BMJ Open Do frailty measures improve prediction of mortality and morbidity following transcatheter aortic valve implantation? An analysis of the UK TAVI registry
}

Glen P Martin, ${ }^{1}$ Matthew Sperrin, ${ }^{1}$ Peter F Ludman, ${ }^{2}$ Mark A deBelder, ${ }^{3}$ Mark Gunning, ${ }^{4,5}$ John Townend, ${ }^{2}$ Simon R Redwood, ${ }^{6}$ Umesh T Kadam, ${ }^{4,5}$ lain Buchan, ${ }^{1,7}$ Mamas A Mamas ${ }^{1,4,5}$

To cite: Martin GP, Sperrin M, Ludman PF, et al. Do frailty measures improve prediction of mortality and morbidity following transcatheter aortic valve implantation? An analysis of the UK TAVI registry. BMJ Open 2018;8:e022543. doi:10.1136/ bmjopen-2018-022543

- Prepublication history and additional material for this paper are available online. To view these files, please visit the journal online (http://dx.doi. org/10.1136/bmjopen-2018022543).

Received 22 February 2018 Revised 9 March 2018 Accepted 25 May 2018
Check for updates

For numbered affiliations see end of article.

Correspondence to

Dr Glen P Martin;

glen.martin@manchester.ac.uk

\section{ABSTRACT}

Objectives Previous studies indicate frailty to be associated with poor outcomes following transcatheter aortic valve implantation (TAVI), but there is limited evidence from multicentre registries. The aim was to investigate the independent association of frailty with TAVI outcomes, and the prognostic utility of adding frailty into existing clinical prediction models (CPMs).

Design The UK TAVI registry incorporated three frailty measures since 2013: Canadian Study of Health and Ageing, KATZ and poor mobility. We investigated the associations between these frailty measures with shortterm and long-term outcomes, using logistic regression to estimate multivariable adjusted ORs, and Cox proportional hazards models to explore long-term survival. We compared the predictive performance of existing TAVI CPMs before and after updating them to include each frailty measure.

Setting All patients who underwent a TAVI procedure in England or Wales between 2013 and 2014.

Participants 2624 TAVI procedures were analysed in this study.

Primary and secondary outcomes The primary endpoints in this study were 30-day mortality and longterm survival. The Valve Academic Research Consortium (VARC)-2 composite early safety endpoint was considered as a secondary outcome.

Results KATZ $<6$ (OR 2.10, 95\% Cl 1.39 to 3.15$)$ and poor mobility (OR $2.15,95 \% \mathrm{Cl} 1.41$ to 3.28 ) predicted 30 -day mortality after multivariable adjustment. All frailty measures were associated with increased odds of the VARC-2 composite early safety endpoint. We observed a significant increase in the area under the receiver operating characteristic curves by approximately $5 \%$ after adding KATZ $<6$ or poor mobility into the TAVI CPMs. Risk stratification agreement was significantly improved by the addition of each frailty measure, with an increase in intraclass correlation coefficient of between 0.15 and 0.31 .

Conclusion Frailty was associated with worse outcomes following TAVI, and incorporating frailty metrics significantly improved the predictive performance of
Strengths and limitations of this study

- An analysis of the association between three frailty measures and clinical outcomes following transcatheter aortic valve implantation (TAVI).

- The study used data from the UK TAVI registry, including all consecutive patients who underwent TAVI in UK between 2013 and 2014.

- A large, contemporary study, which investigated the impact of frailty on outcomes and mortality prediction post-TAVI from a national perspective.

- Only three subjective frailty measures were available, with objective frailty tests not recorded.

- This retrospective analysis could not compare outcomes across frailty groups in patients with untreated aortic stenosis, or those undergoing surgical replacement.

existing CPMs. Physician-estimated frailty measures could aid TAVI risk stratification, until more objective scales are routinely collected.

\section{INTRODUCTION}

Transcatheter aortic valve implantation (TAVI) has emerged as an effective treatment strategy for patients with aortic stenosis who are intermediate-to-high operative risk. ${ }^{1-3}$ To this end, surgical clinical prediction models (CPMs), such as the EuroSCORE or the Society of Thoractic Surgeons (STS) model, have previously been used to estimate risk, but TAVI-specific CPMs are emerging from national registries: examples include the FRANCE-2 model ${ }^{4}$ the OBSERVANT model ${ }^{5}$ and the American College of Cardiology (ACC) Transcatheter Valve Therapy model. ${ }^{6}$ However, these models do not usually incorporate measures of frailty and disability into geriatric prescreening risk assessment. 
Frailty is an emerging concept in clinical science and is defined as an age-related decline in the resilience to stressors caused by deterioration in multiple physiological systems. ${ }^{7}$ Consequently, there is a growing evidence base of associations between frailty and poor outcomes after TAVI. ${ }^{8-13}$ Indeed, patient's frailty, dependencies in activities of daily living (ADL) and cognitive function are increasingly being considered in the decision-making process for TAVI eligibility. ${ }^{14}$ However, measures of frailty are rarely incorporated into many of the currently available CPMs, which has potentially contributed to the moderate predictive performance of such models outside their development datasets. ${ }^{15-17}$ The recent recording of measures relating to frailty/disability in national cohorts presents novel opportunities to incorporate them into future iterations of existing TAVI CPMs.

Therefore, the aim was to investigate the effect of frailty and disability on mortality and morbidity in a national TAVI cohort and to examine the prognostic utility of adding frailty/disability into existing TAVI CPMs.

\section{METHODS}

\section{UK TAVI registry}

The UK TAVI registry prospectively collects 95 variables (including patient demographics, risk factors for intervention and within-hospital adverse outcomes), for every TAVI procedure conducted in the UK. ${ }^{18}$ This analysis used data from patients in England and Wales, for whom all-cause mortality was linked from the Office for National Statistics. The study period for this analysis was January 2013 to December 2014, corresponding to the time in which the UK registry recorded three variables that related to frailty/disability. Specifically, the registry recorded the Canadian Study of Health and Ageing (CSHA)-estimated frailty scale, ${ }^{19} \mathrm{KATZ}$ ADL dependency ${ }^{20}$ and a physician-estimated poor mobility (as defined in the EuroSCORE II model $\left.{ }^{21}\right)$. Frailty groups were defined separately across the three measures with the full definitions of each group given in table 1. Dichotomising CSHA and KATZ scores into two categories was based on the empirical median value (CSHA='apparently vulnerable' and $\mathrm{KATZ}=6)$, and on the original publication of CSHA. ${ }^{19}$ Additionally, for this analysis, we defined a composite score to incorporate information from all three of the measures, with the definition given in table 1 .

\section{Study endpoints}

The primary endpoints in this study were 30-day mortality and long-term survival. As a secondary endpoint, we investigated the Valve Academic Research Consortium (VARC)-2 composite early safety endpoint, which is defined as a failure in any of the following outcomes by 30 days: all-cause mortality, stroke, life-threatening bleeding, stage $2 / 3$ acute kidney injury, coronary artery obstruction requiring intervention, major vascular complications or valve-related dysfunction requiring a repeat procedure. ${ }^{14}$

Table 1 Frailty grouping definitions by each frailty/disability measure

\begin{tabular}{|c|c|c|}
\hline $\begin{array}{l}\text { Frailty/disability } \\
\text { measure }\end{array}$ & Scoring system & Frailty definition used in this analysis \\
\hline $\mathrm{CSHA}^{*}$ & $\begin{array}{l}\text { A physician-estimated frailty score, based on the } \\
\text { following options: (1) very fit, (2) well,; (3) well with } \\
\text { treated comorbid disease, (4) apparently vulnerable, } \\
\text { (5) mildly frail with limited dependence for activities } \\
\text { of daily living (ADL), (6) moderately frail requiring } \\
\text { help with ADL, (7) severely frail being completely } \\
\text { dependent. }\end{array}$ & $\begin{array}{l}\text { CSHA options of } 5-7 \text { were used to define } \\
\text { CSHA frail patients; options 1-4 were } \\
\text { classed as CSHA non-frail. }\end{array}$ \\
\hline $\mathrm{KATZ}^{*}$ & $\begin{array}{l}\text { 0-6 points scale assessing dependency in the } \\
\text { following ADL: (1) bathing, (2) dressing, (3) toileting, (4) } \\
\text { transferring, (5) continence, (6) Feeding. }\end{array}$ & $\begin{array}{l}\text { Any patient with a KATZ score }<6 \text { points } \\
\text { compared with those with } K A T Z=6 \text {. }\end{array}$ \\
\hline Poor mobility & $\begin{array}{l}\text { A physician-estimated indication of any severe } \\
\text { impairment of mobility that is secondary to } \\
\text { musculoskeletal or neurological dysfunction. }\end{array}$ & $\begin{array}{l}\text { Any patient defined as having poor mobility } \\
\text { compared with those defined as having } \\
\text { normal mobility. }\end{array}$ \\
\hline
\end{tabular}

*Dichotomising of CSHA and KATZ into two groups was based on the median level observed in the TAVI registry (see online supplementary figures 1 and 2 for the distribution of these scores).

CSHA, Canadian Study of Health and Ageing; TAVI, transcatheter aortic valve implantation. 


\section{Statistical analysis}

Every variable with missing data was imputed using multiple imputation that generated 10 imputed datasets. ${ }^{22}$ The imputation model for each variable included the majority of other variables in the UK TAVI registry and all considered endpoints. ${ }^{23}$ Imputed frailty measures and outcomes were not used, and instead were returned to the original (missing) values. ${ }^{24}$ Subsequently, patients missing data on CSHA, KATZ, poor mobility and/ or missing life status were removed from the analysis; patients with missing VARC-2 composite early safety were only removed from the analysis of that outcome. All analyses were undertaken in each imputed dataset separately, with the results pooled according to Rubin's rules. ${ }^{22}$

For exploratory analysis, we obtained spatial maps of England at a National Health Service (NHS) regional level (a high-level geographical structure partitioning England into 13 regions) and of Wales, from the Office for National Statistics. By linking the clinical commission group of each patient to the corresponding NHS region, we calculated the proportion of frail patients in the study population across England and Wales.

Odds Ratios (ORs) for binary endpoints were estimated using logistic regression, with both unadjusted and adjusted ORs reported. Multivariable models adjusted for the following variables: total centre volume, age, sex, diabetes status, smoking status, creatinine, renal failure, previous myocardial infarction, pulmonary disease, neurological disease, extracardiac arteriopathy, calcification of ascending aorta, atrial fibrillation/flutter, previous cardiac surgery, previous percutaneous coronary intervention, height, weight, critical preoperative status, Canadian Cardiovascular Society grading class 4, New York Heart Association (NYHA) class $\geq$ III, aortic valve area and peak gradient, left ventricular ejection fraction (LVEF) $<50 \%$, one or more diseases vessels, left main stem disease, non-elective procedure indication and non-transfemoral access indication.

Long-term survival was assessed non-parametrically using Kaplan-Meier plots and strata were compared using the log-rank test. Multivariable adjustment was performed using Cox proportional hazards models, using the same variables as above to adjust the frailty indication hazard ratio (HR) for measured confounding. To account for non-proportional hazards, time was split into strata of 0-180 days, 180-365 days and $>365$ days, with frailty-indication-by-time-indicator interactions included in the Cox proportional hazards models.

The effect on predictive performance of adding CSHA-estimated frailty, KATZ ADL dependency or physician-estimated poor mobility into the existing TAVI CPMs (FRANCE-2, OBSERVANT and ACC) was considered using model updating techniques. ${ }^{25-27}$ Mathematical details of model updating techniques are given in the supplementary methods. In short, CSHA, KATZ and poor mobility were added (both separately and sequentially for each measure) into an existing CPM by fitting a logistic regression model of 30-day mortality, with both the linear predictor of the considered TAVI CPM and at least one of the frailty measures as covariates. The likelihood ratio test (LRT) was used to test for significant improvement in model fit before and after model updating. Additionally, the area under the receiver operating characteristic curve (AUC) was calculated for each model and compared using a DeLong comparison. ${ }^{28}$ Finally, intraclass correlation coefficient (ICC) estimates and their 95\% CIs were calculated based on an absolute-agreement, two-way random effects model to indicate the risk-prediction agreement between the TAVI CPMs both before and after the addition of CSHA, KATZ or poor mobility.

R V.3.4. $0^{29}$ was used for all statistical analyses. Graphical plots were made using the ggplot2 package ${ }^{30}$ and the mice package was used for the multiple imputation. ${ }^{31}$

\section{Patient and public involvement}

No patients were involved in the design or conducting of this study.

\section{RESULTS}

Between January 2013 and December 2014, n=3073 patients underwent a TAVI procedure in England and Wales. After excluding 104 patients with missing life status and 345 patients with any missing frailty measure, 2624 patients were analysed in this study. Due to the relative high proportion of exclusions (14.6\%), we examined baseline characteristics of included patients compared with those excluded (online supplementary table 1). Most of the baseline characteristics were similar between the study group and the excluded group, with the exception of access route, proportion of calcified aorta and NYHA $\geq$ III.

A total of 1043 patients $(39.7 \%)$ had CSHA-estimated frailty (online supplementary figure 1), 846 patients $(32.2 \%)$ had ADL dependency $(\mathrm{KATZ}<6)$ (online supplementary figure 2) and 591 patients $(22.5 \%)$ had physician-estimated poor mobility. Figure 1 shows a Venn diagram of the overlap in classification across the three measures. The central segment of the Venn diagram $(\mathrm{n}=297)$ is the group defined as 'severely frail' by the composite score, with the other segments $(n=1169)$ showing the 'moderately frail' group. The disagreement in figure 1 may relate to both the relative imprecision and subjectivity of each frailty measure and that the different measures assess disparate aspects of frailty.

Baseline characteristics and the proportion of missing data for the whole cohort are presented in table 2. Comparisons of baseline characteristics across CSHA-estimated frailty, KATZ ADL dependency and physician-estimated poor mobility groups are given in online supplementary tables 2-4, respectively. CSHA-estimated frail patients were more likely female $(p<0.001)$, with higher proportions of NYHA $\geq$ III $(p<0.001)$, LVEF $<50 \% \quad(p=0.001)$ and non-elective procedures $(p<0.001)$, but with lower numbers of CSHA-estimated frail patients having a previous cardiac surgery $(\mathrm{p}<0.001)$. 
CSHA-estimated frail $(n=1043)$

KATZ<6 $(n=846)$

Physician-estimated poor mobility $(n=591)$

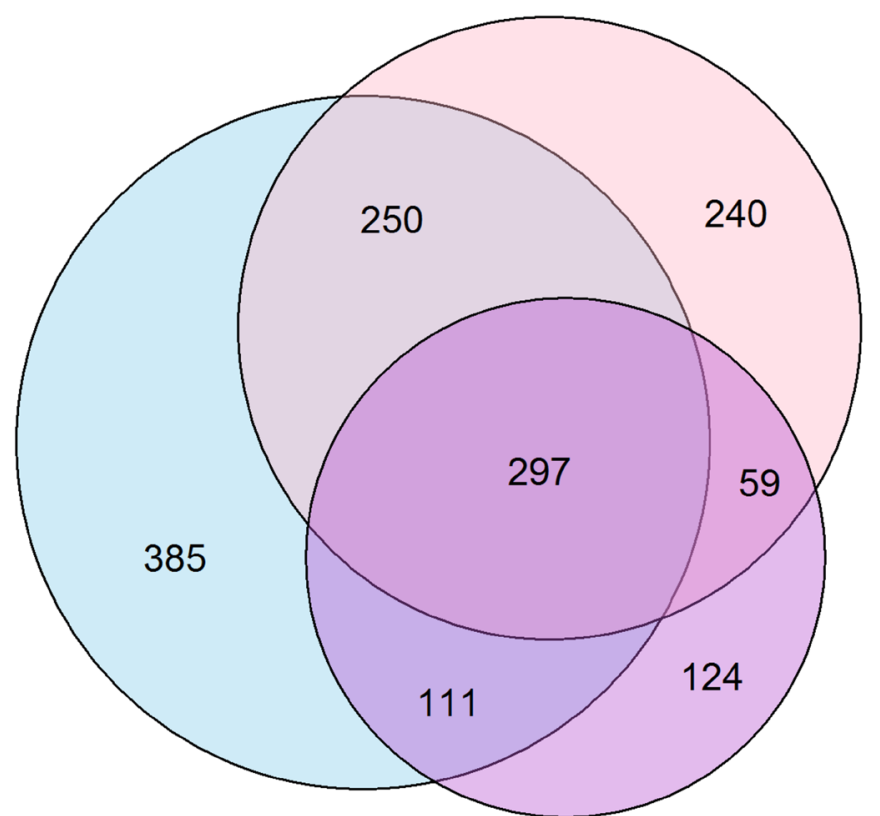

Figure 1 Venn diagram showing the overlap in the different definitions of frailty/disability across CSHA-estimated frailty, $\mathrm{KATZ}<6$ and physician-estimated poor mobility; the sizes of each segment are proportional to the segment sample sizes. CSHA, Canadian Study of Health and Ageing.

Similar differences were observed between KATZ ADL dependency (online supplementary table 3 ) and between physician-estimated poor mobility groups (online supplementary table 4 ).

There was large spatial heterogeneity in the proportion of TAVI procedures conducted in patients estimated as having poor mobility, KATZ $<6$ or CSHA-estimated frailty (online supplementary figure 3 ). For example, proportions of physician-estimated poor mobility patients across NHS regions ranged from $6.5 \%$ to $42.7 \%$; NHS England North (Lancashire and Greater Manchester) had the highest proportion of patients with KATZ $<6$ and CSHA-estimated frailty, while NHS England South (Wessex) had the highest proportion of physician-estimated poor mobility patients.

\section{Frailty and post-TAVI outcomes}

Incremental increases in components of CSHA and KATZ were associated with increased crude 30-day mortality rates (online supplementary figures 2 and 3 ). Specifically, CSHA-estimated frail patients had higher crude 30-day mortality, but this was not significant after multivariable adjustment (table 3). In contrast, physician-estimated poor mobility and KATZ $<6$ were significantly associated with increased odds of 30-day mortality after multivariable adjustment. All three of the considered frailty measures were independently associated with increased VARC-2 composite early safety endpoint (table 3 ). Similarly, those
Table 2 Baseline characteristics and number of missing data within the whole cohort

\begin{tabular}{|c|c|c|}
\hline Variable & $\begin{array}{l}\text { Whole cohort } \\
(n=2624)\end{array}$ & Missing, n (\%) \\
\hline Age, mean (SD) & $81.2(7.58)$ & $0(0.00)$ \\
\hline Female, n (\%) & $1192(45.4)$ & $1(0.04)$ \\
\hline Diabetic, n (\%) & $641(24.4)$ & $2(0.08)$ \\
\hline Smoker, n (\%) & 1316 (50.2) & $45(1.71)$ \\
\hline Creatinine, mean (SD) & $110.9(60.5)$ & $6(0.23)$ \\
\hline Renal failure ${ }^{\star}, \mathrm{n}(\%)$ & $143(5.45)$ & $10(0.38)$ \\
\hline Previous MI, n (\%) & $558(21.3)$ & $2(0.08)$ \\
\hline Pulmonary disease, $\mathrm{n}(\%)$ & $791(30.1)$ & $3(0.11)$ \\
\hline Neurological disease, n (\%) & $441(16.8)$ & $1(0.04)$ \\
\hline $\begin{array}{l}\text { Extracardiac arteriopathy, } \\
\mathrm{n}(\%)\end{array}$ & $555(21.2)$ & $5(0.19)$ \\
\hline $\begin{array}{l}\text { Calcification of ascending } \\
\text { aorta, } \%(n)\end{array}$ & $378(14.4)$ & $22(0.84)$ \\
\hline Atrial fibrillation, n (\%) & $700(26.7)$ & $23(0.88)$ \\
\hline $\begin{array}{l}\text { Previous cardiac surgery, } \\
\mathrm{n}(\%)\end{array}$ & $799(30.4)$ & $5(0.19)$ \\
\hline Previous PCI, n (\%) & $524(20.0)$ & $2(0.08)$ \\
\hline Height, mean (SD) & $1.64(0.10)$ & $19(0.72)$ \\
\hline Weight, mean (SD) & $75.0(17.1)$ & $18(0.69)$ \\
\hline CCS class $4, \mathrm{n}(\%)$ & $24(0.91)$ & $3(0.11)$ \\
\hline NYHA $\geq I I I, n(\%)$ & $1985(75.6)$ & $6(0.23)$ \\
\hline Aortic valve area, mean (SD) & $0.69(0.23)$ & $147(5.60)$ \\
\hline $\begin{array}{l}\text { Aortic valve peak gradient, } \\
\text { mean (SD) }\end{array}$ & $71.2(26.2)$ & $129(4.92)$ \\
\hline LVEF <50\%, n (\%) & $948(36.1)$ & $12(0.46)$ \\
\hline $\begin{array}{l}\text { One or more diseased } \\
\text { vessels, } \mathrm{n}(\%)\end{array}$ & $1058(40.3)$ & $47(1.79)$ \\
\hline $\begin{array}{l}\text { Left main stem disease, } n \\
(\%)\end{array}$ & $103(3.93)$ & $75(2.86)$ \\
\hline Non-elective procedure, $\mathrm{n}$ & $365(13.9)$ & $2(0.08)$ \\
\hline
\end{tabular}

(\%)

\begin{tabular}{lll} 
Access site & & \\
\hline Transfemoral, $\mathrm{n}(\%)$ & $2127(81.1)$ & $3(0.11)$ \\
\hline Transapical, $\mathrm{n}(\%)$ & $249(9.49)$ & $3(0.11)$ \\
Subclavian, $\mathrm{n}(\%)$ & $85(3.24)$ & $3(0.11)$ \\
Other, $\mathrm{n}(\%)$ & $160(6.10)$ & $3(0.11)$ \\
\hline
\end{tabular}

*Defined as creatinine $>200 \mu \mathrm{mol} / \mathrm{L}$ or dialysis for renal failure. CCS, Canadian Cardiovascular Society; LVEF, left ventricular ejection fraction; MI, myocardial Infarction; NYHA, New York Heart Association; $\mathrm{PCl}$, percutaneous coronary intervention.

defined as frail across all three of CSHA, KATZ and poor mobility (ie, severely frail within the composite score) had significantly higher multivariable adjusted odds of 30-day mortality and composite early safety compared with patients defined as non-frail by the composite score (online supplementary table 5). 
Table 3 Short-term outcomes across CSHA-estimated frailty, KATZ ADL dependency and physician-estimated poor mobility groups

\begin{tabular}{|c|c|c|c|c|}
\hline Outcome & $\begin{array}{l}\text { CSHA-estimated frail } \\
(n=1043)\end{array}$ & $\begin{array}{l}\text { CSHA-estimated non-frail } \\
(n=1581)\end{array}$ & $\begin{array}{l}\text { Univariable OR } \\
(95 \% \mathrm{Cl})^{*}\end{array}$ & $\begin{array}{l}\text { Multivariable OR } \\
(95 \% \mathrm{Cl})^{\star}\end{array}$ \\
\hline 30-day mortality & $57 / 1043(5.47 \%)$ & $51 / 1581(3.23 \%)$ & $1.73(1.18$ to 2.55$)$ & 1.46 (0.96 to 2.23 ) \\
\hline Early safety & 187/1014 (18.44\%) & $190 / 1540(12.34 \%)$ & 1.61 (1.29 to 2.00$)$ & 1.45 (1.14 to 1.84$)$ \\
\hline Outcome & KATZ <6 $(n=846)$ & KATZ $=6(n=1778)$ & $\begin{array}{l}\text { Univariable OR } \\
(95 \% \mathrm{CI})^{*}\end{array}$ & $\begin{array}{l}\text { Multivariable OR } \\
(95 \% \mathrm{Cl})^{\star}\end{array}$ \\
\hline 30-day mortality & $58 / 846(6.86 \%)$ & $50 / 1778(2.81 \%)$ & 2.54 (1.73 to3.75) & 2.10 (1.39 to3.15) \\
\hline Early safety & 150/827 (18.14\%) & 227/1727 (13.14\%) & 1.46 (1.17 to 1.83$)$ & 1.28 (1.01 to 1.63 ) \\
\hline Outcome & Poor mobility $(n=591)$ & Normal mobility $(n=2033)$ & $\begin{array}{l}\text { Univariable OR } \\
(95 \% \mathrm{Cl})^{*}\end{array}$ & $\begin{array}{l}\text { Multivariable OR } \\
(95 \% \mathrm{Cl})^{\star}\end{array}$ \\
\hline 30-day mortality & $46 / 591(7.78 \%)$ & $62 / 2033$ (3.05\%) & 2.68 (1.81 to 3.98$)$ & 2.15 (1.41 to 3.28$)$ \\
\hline Early safety & $116 / 571$ (20.32\%) & 261/1983 (13.16\%) & 1.68 (1.32 to 2.14$)$ & 1.45 (1.12 to 1.88$)$ \\
\hline
\end{tabular}

${ }^{*}$ Bold items indicate significant results.

ADL, activities of daily living; CSHA, Canadian Study of Health and Ageing.

Overall survival was $95.9 \%, 85.2 \%$ and $76.3 \%$ at 30 days, 1 year and 2 years, respectively. Survival was significantly worse for patients with CSHA-estimated frailty $(\mathrm{p}<0.0001)$, KATZ $<6 \quad(\mathrm{p}<0.0001)$, physician-estimated poor mobility $(\mathrm{p}<0.001)$, and across the composite frailty
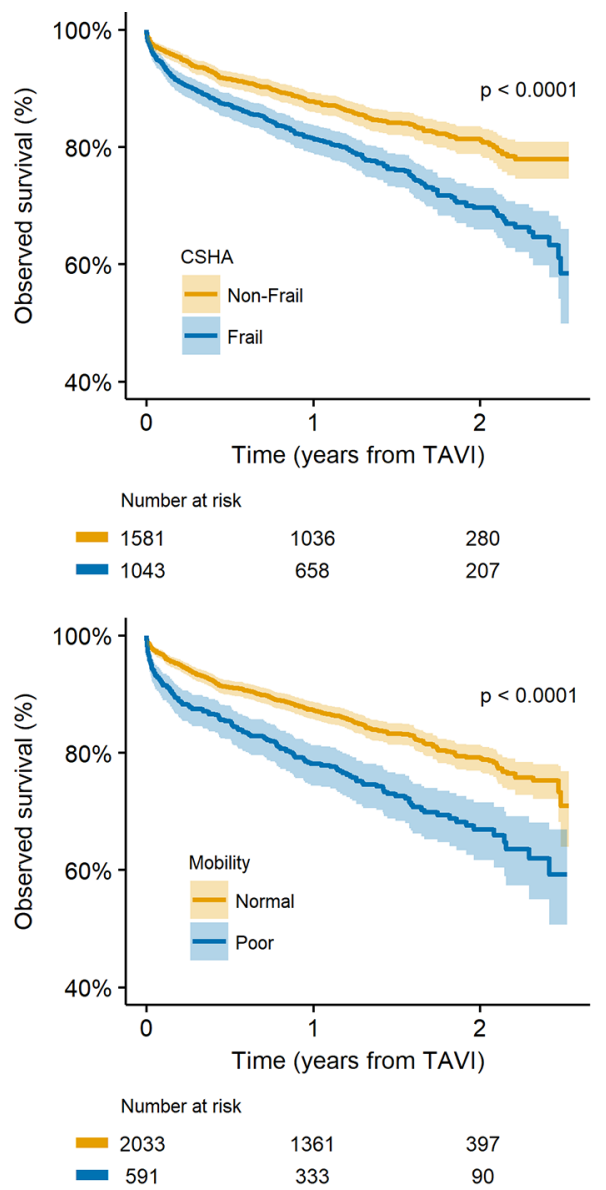

groups $(\mathrm{p}<0.0001)$ (figure 2$)$. The multivariable time-dependent Cox proportional hazards models indicated that hazards of mortality were significantly higher for those with KATZ $<6$ or physician-estimated poor mobility within 1-year post-TAVI (table 4); after 1 year, multivariable
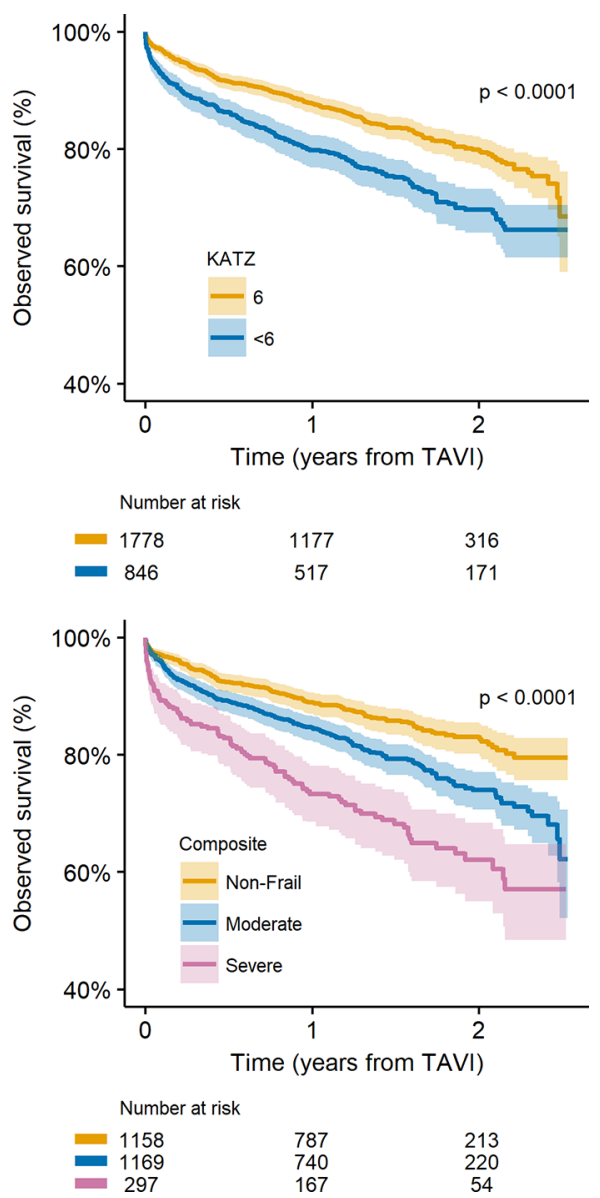

Figure 2 Kaplan-Meier plots across CSHA-estimated frailty (top-left), KATZ activities of daily living dependency (top-right), physician-estimated poor mobility (bottom-left) and the composite frailty score (bottom-right). Definitions are described in table 1. CSHA, Canadian Study of Health and Ageing; TAVI, transcatheter aortic valve implantation. 


\begin{tabular}{|c|c|c|}
\hline $\begin{array}{l}\text { Frailty-by-time } \\
\text { interaction }\end{array}$ & $\begin{array}{l}\text { Univariable HR } \\
(95 \% \mathrm{Cl})^{\star}\end{array}$ & $\begin{array}{l}\text { Multivariable HR } \\
(95 \% \mathrm{Cl})^{\star}\end{array}$ \\
\hline \multicolumn{3}{|c|}{ CSHA-estimated frail } \\
\hline $0-180$ days & 1.56 (1.22 to 1.98$)$ & 1.29 (1.00 to 1.66$)$ \\
\hline $180-365$ days & 1.63 (1.12 to 2.38$)$ & 1.37 (0.94 to 2.01$)$ \\
\hline$>365$ days & 1.85 (1.32 to 2.60 ) & 1.61 (1.14 to 2.29 ) \\
\hline \multicolumn{3}{|l|}{$\mathrm{KATZ}<6$} \\
\hline $0-180$ days & 1.71 (1.34 to 2.18 ) & 1.55 (1.21 to 1.99$)$ \\
\hline 180-365 days & 1.86 (1.28 to 2.71$)$ & 1.74 (1.19 to 2.55$)$ \\
\hline$>365$ days & 1.25 (0.88 to 1.78$)$ & 1.23 (0.86 to 1.75$)$ \\
\hline \multicolumn{3}{|c|}{ Physician-estimated poor mobility } \\
\hline $0-180$ days & 1.74 (1.34 to 2.25$)$ & 1.50 (1.15 to 1.96$)$ \\
\hline $180-365$ days & 2.06 (1.39 to 3.06$)$ & 1.84 (1.24 to 2.75$)$ \\
\hline$>365$ days & 1.50 (1.03 to 2.20$)$ & 1.36 (0.92 to 2.00$)$ \\
\hline
\end{tabular}

*Bold items indicate significant results.

CSHA, Canadian Study of Health and Ageing.

adjusted hazards were not significantly different for these measures. CSHA-estimated frailty had significantly increased hazards of mortality $0-180$ days and $>365$ days post-TAVI, but hazards were not significantly different between these time windows. Quantitatively, similar results were found across the composite score frailty groups.

\section{Addition of frailty in TAVI CPMs}

Table 5 gives the discrimination of each TAVI CPM for predicting 30-day mortality both before and after the addition of each frailty measure. The LRT indicated a significant improvement in model fit by adding CSHA-estimated frailty into the FRANCE-2 model $(\mathrm{p}=0.037)$, the OBSERVANT model $(\mathrm{p}=0.020)$ and the ACC model $(p=0.048)$. Adding KATZ $<6$ into the TAVI models significantly improved the AUC of both the FRANCE-2 CPM $(\mathrm{p}=0.047)$ and the OBSERVANT CPM $(\mathrm{p}=0.007)$, with the LRT indicating a significant improvement in model fit for all three TAVI CPMs $(p<0.001)$. Equally, physician-estimated poor mobility significantly improved the fit of all three models (LRT $\mathrm{p}<0.001$ ) and significantly increased the AUC of the OBSERVANT $(\mathrm{p}=0.006)$ and the ACC $(p=0.030)$ CPMs by $7 \%$ and $5 \%$, respectively. A forward stepwise selection of all three measures resulted in $\mathrm{KATZ}<6$ and physician-estimated poor mobility being added into each of the existing TAVI CPMs (table 5), that is, CSHA-estimated frailty did not significantly improve the predictive performance of the existing TAVI models after inclusion of KATZ $<6$ and physician-estimated poor mobility.

Finally, the absolute-agreement ICC between the original versions of each TAVI CPM was 0.39 (95\% CI 0.27 to 0.49 ), which increased to 0.65 (95\% CI 0.63 to 0.67 ), 0.78 (95\% CI 0.76 to 0.79$)$ and 0.81 (95\% CI 0.79 to 0.82 ) on adding CSHA-estimated frailty, KATZ $<6$ or physician-estimated poor mobility, respectively. Thus, the patient-level
Table 5 Discrimination of each TAVI CPM at predicting 30-day mortality before and after the addition of each frailty measure

\begin{tabular}{|c|c|c|}
\hline Model & AUC $(95 \% \mathrm{Cl})$ & P values* \\
\hline \multicolumn{3}{|l|}{ FRANCE-2 } \\
\hline Original & 0.62 (0.57 to 0.68$)$ & N/A \\
\hline Updated with CSHA only & 0.64 (0.58 to 0.69$)$ & 0.412 \\
\hline Updated with KATZ only & 0.67 (0.61 to 0.72$)$ & 0.047 \\
\hline $\begin{array}{l}\text { Updated with poor } \\
\text { mobility only }\end{array}$ & 0.67 (0.62 to 0.72$)$ & 0.058 \\
\hline $\begin{array}{l}\text { Updated with stepwise } \\
\text { selection† }\end{array}$ & 0.68 (0.63 to 0.73$)$ & 0.025 \\
\hline \multicolumn{3}{|l|}{ Observant } \\
\hline Original & 0.56 (0.50 to 0.62$)$ & N/A \\
\hline Updated with CSHA only & 0.59 (0.53 to 0.65$)$ & 0.129 \\
\hline Updated with KATZ only & 0.62 (0.56 to 0.68$)$ & 0.007 \\
\hline $\begin{array}{l}\text { Updated with poor } \\
\text { mobility only }\end{array}$ & 0.63 (0.57 to 0.69$)$ & 0.006 \\
\hline $\begin{array}{l}\text { Updated with stepwise } \\
\text { selection† }\end{array}$ & 0.64 (0.58 to 0.71$)$ & 0.002 \\
\hline \multicolumn{3}{|l|}{ ACC } \\
\hline Original & 0.63 (0.58 to 0.68$)$ & $\mathrm{N} / \mathrm{A}$ \\
\hline Updated with CSHA only & 0.64 (0.59 to 0.69$)$ & 0.605 \\
\hline Updated with KATZ only & 0.67 (0.61 to 0.72$)$ & 0.069 \\
\hline $\begin{array}{l}\text { Updated with poor } \\
\text { mobility only }\end{array}$ & 0.68 (0.63 to 0.73$)$ & 0.030 \\
\hline $\begin{array}{l}\text { Updated with stepwise } \\
\text { selectiont }\end{array}$ & 0.68 (0.63 to 0.74$)$ & 0.036 \\
\hline
\end{tabular}

*The DeLong $p$ value compares the AUC of predicting 30-day mortality using the original TAVI CPM with that using each corresponding updated version.

†Forward selection across the three frailty measures resulted in KATZ $<6$ and physician-estimated poor mobility being added into each existing TAVI CPM.

ACC, American College of Cardiology; AUC, area under the curve; CPM, clinical prediction model; CSHA, Canadian Study of Health and Ageing; N/a, not applicable; TAVI, transcatheter aortic valve implantation.

agreement in risk prediction between the three TAVI CPMs was significantly improved after adding any of CSHA, KATZ or poor mobility into the models.

\section{DISCUSSION}

The findings from this study can be summarised as follows: (1) KATZ $<6$ and physician-estimated poor mobility were independently associated with increased 30-day mortality, and all three considered frailty measures were associated with increased VARC-2 composite early safety; (2) patients with $\mathrm{KATZ}<6$ and physician-estimated poor mortality had significantly worse survival up to 1-year post-TAVI; (3) the addition of KATZ and physician-estimated poor mobility into existing TAVI CPMs significantly improved the 
discrimination and patient-level risk-stratification agreement of the models.

\section{Frailty and clinical outcomes following TAVI}

Given that frailty is an indicator of general health status and vulnerability among elderly patients, ${ }^{7}$ it is naturally under study in the TAVI field. The current study supports and expands the findings from previous studies that have shown associations between frailty and poor TAVI outcomes. ${ }^{8-13} 32-34$ For instance, a previous analysis of a single UK centre showed that poor mobility strongly predicted survival following TAVI ${ }^{10}$; the current study supports this finding at the national level, in showing that the odds of 30-day mortality in those with physician-estimated poor mobility were 2.15 times higher compared with normal mobility. Similarly, a multicentre investigation of the Japanese registry found that a semiquantitative Clinical Frailty Scale was associated with increased 30-day and 1-year mortality. ${ }^{12}$ Together, the current and previous results suggest that frailty/disability is an indicator of worse outcomes post-TAVI, despite the heterogeneity in frailty measures used across the existing evidence base. AHA/ACC guidelines currently indicate that KATZ, gait speed and grip strength should be used in the assessment of surgical risk, ${ }^{35}$ with the emerging data suggesting that similar recommendations should be made for TAVI risk assessment and prediction.

However, implementing this emerging evidence may prove difficult without consensus regarding the most clinically useful measure of frailty in TAVI patients. By comparing the predictive performance of seven different frailty scales, Afilalo et al recently recommended that the 'Essential Frailty Toolset', which includes multiple domains of frailty (motor skills, cognition and nutritional/physiological factors), be used in TAVI patients. ${ }^{11}$ Data on such frailty domains were unavailable for the current study, with the three subjective measures collected within the UK TAVI registry mainly using measurements of ADL. Nonetheless, it is conceivable that assessment of ADL (eg, KATZ) could provide a simple mechanism of informing part of the risk assessment process for TAVI, until more objective frailty scales are routinely collected. For instance, a previous multicentre study by Alfredsson et al showed that an objective measure of gait speed was associated with 30 -day mortality following TAVI, ${ }^{32}$ but such measures are rarely recorded in national registries, which would currently limit their use to aid risk prediction/stratification in TAVI patients.

Moreover, outcomes after TAVI should consider both mortality and quality of life in the context of the elderly patients who predominantly undergo TAVI. Previous work has shown associations between frailty and quality of life ${ }^{36}$ and a contemporary TAVI CPM that was derived to predict poor outcome (defined as mortality and/ or reduced quality of life) included measures of frailty, functional status and cognitive decline. ${ }^{37}$ Within the current study, indicators of quality of life were not available, which should be noted as a limitation of the study.
Consequently, further studies are needed to investigate the effect of frailty on endpoints such as quality of life or hospital readmission, which are increasingly used as a measure of futility in TAVI patients.

\section{Prognostic utility of frailty}

Prognostic risk prediction for TAVI is an ongoing research area, with existing TAVI CPMs reporting only moderate performance when validated. ${ }^{4-6}{ }^{16}$ We found that adding indicators of dependency in ADL $(\mathrm{KATZ}<6)$ or physician-estimated poor mobility significantly improved the predictive performance and patient-level risk-stratification agreement of the TAVI models. This supports previous work that has demonstrated improvements in predictive performance of the EuroSCORE and STS models through the addition of frailty measures. ${ }^{11} 123940$ Consequently, the heart team should consider frailty measures in addition to the multiple comorbidities that are reflected in existing risk scores, preferably by the inclusion of frailty directly into the risk prediction. We recommend that future iterations of existing and new TAVI risk models should include markers of frailty/disability. Arguably, one should regard frailty as a spectrum, rather than a binary phenomenon; however, the sample size of the current study restricted our ability to subclassify KATZ and CSHA into their individual components. Moreover, the marginal improvement in predictive performance demonstrated after the inclusion of frailty/disability measures into existing TAVI CPMs, suggests that these measures cannot overcome the need to discover novel risk factors in this patient cohort, or the need to predict endpoints other than mortality (eg, readmission or quality of life).

Additionally, the quantification of TAVI risk by using subjective measures of frailty could be problematic in situations of low inter-rater reliability. The current study demonstrated large spatial variability in the proportion of TAVI procedures conducted on 'frail' patients, but the subjectivity of CSHA and KATZ means that we were unable to separate genuine spatial differences from systematic variation in how different teams define/record these measures. This provides further indication for the need to refine the assessment of frailty in TAVI patients, since the current methods were derived for different purposes.

\section{Study limitations}

The strength of this study is that it is a large, contemporary study, which has investigated the impact of frailty on outcomes and mortality prediction post-TAVI from a national perspective. However, several limitations need to be considered. First, only three subjective frailty measures were available, with objective frailty tests such as $6 \mathrm{~min}$ walk distance, grip strength or gait speed not recorded. Second, unmeasured confounders inherent in most observational studies potentially influence conclusions. Third, given that we could only analyse TAVI patients in $2013 / 2014$, this retrospective study was underpowered to investigate endpoints with small event rates such as 
bleeding or myocardial infarction. As the volume of frailty data increases, future studies will be able to investigate such outcomes. Fourth, the current study had a significant proportion of patients who were removed due to missing frailty measures and/or missing life status, which could potentially bias the results. However, the proportion of missing data in other variables was low and we implemented a multiple imputation procedure. Finally, given that this was a retrospective analysis of a national TAVI registry, we could not examine frailty in untreated patients with aortic stenosis, and neither could we compare the outcomes with patients treated through surgical aortic valve replacement. Thus, associations between frailty and the propensity for conservative treatment could not be explored, with corresponding potential for selection bias. Specifically, the analysis highlights potential measures to predict the expected outcomes after TAVI, but not the expected outcomes without TAVI.

\section{CONCLUSIONS}

Frailty and disability, as estimated by KATZ, CSHA and poor mobility, was significantly associated with mortality and morbidity after TAVI. The predictive performance and patient-level risk-stratification agreement were significantly improved by updating existing TAVI CPMs to include measures of frailty/ADL dependency. Hence, physician-estimated frailty/disability measures could aid TAVI risk stratification, until scales that are more objective are routinely collected.

\section{Author affiliations}

${ }^{1}$ Farr Institute, Faculty of Biology, Medicine and Health, University of Manchester, Manchester Academic Health Science Centre, Manchester, UK

${ }^{2}$ Queen Elizabeth Hospital, Birmingham, UK

${ }^{3}$ The James Cook University Hospital, Middlesbrough, UK

${ }^{4}$ Keele Cardiovascular Research Group, Institute of Applied Clinical Science and Centre for Prognosis Research Group, Institute of Primary Care and Health Sciences, Keele University, Stoke-on-Trent, UK

${ }^{5}$ Academic Department of Cardiology, Royal Stoke Hospital, Stoke-on-Trent, UK

${ }^{6}$ Guy's and St Thomas' NHS Foundation Trust, London, UK

${ }^{7}$ Microsoft Research, Cambridge, UK

Acknowledgements We would like to acknowledge all participating centres for collecting the data and the National Institute for Cardiovascular Outcomes Research (NICOR) for providing the UK TAVI registry extract for this study.

Contributors GPM, MS and MAM made substantial contributions to the concept of the work in addition to performing the analysis. GPM drafted the initial version of the manuscript. GPM, MS, PFL, MAd, MG, JT, SRR, UTK, IB and MAM interpreted the results, revised the paper critically for important intellectual content and approved the final version of the paper. All authors agreed to be accountable for all aspects of the work.

Funding This research was funded by the Medical Research Council, through the Health e-Research Centre, University of Manchester (MR/K006665/1) and the North Staffordshire Heart Committee.

Competing interests None declared.

Patient consent Not required.

Ethics approval The National Institute for Cardiovascular Outcomes Research (NICOR) which includes the UK TAVI registry has support under section 251 of the National Health Service Act 2006 to use patient information for medical research without informed consent. Further ethical approval was not required under current
National Health Service research governance arrangements, as all data analysed in the study were pseudonymised and contained no patient identifiable information.

Provenance and peer review Not commissioned; externally peer reviewed.

Data sharing statement The data that this research was conducted on are available from the National Institute for Cardiovascular Outcomes Research (NICOR) after undertaking an application process.

Open access This is an open access article distributed in accordance with the terms of the Creative Commons Attribution (CC BY 4.0) license, which permits others to distribute, remix, adapt and build upon this work, for commercial use, provided the original work is properly cited. See: http://creativecommons.org/ licenses/by/4.0/

(C) Article author(s) (or their employer(s) unless otherwise stated in the text of the article) 2018. All rights reserved. No commercial use is permitted unless otherwise expressly granted.

\section{REFERENCES}

1. Leon MB, Smith CR, Mack M, et al. Transcatheter aortic-valve implantation for aortic stenosis in patients who cannot undergo surgery. N Engl J Med 2010;363:1597-607.

2. Smith $\mathrm{CR}$, Leon MB, Mack MJ, et al. Transcatheter versus surgical aortic-valve replacement in high-risk patients. $N$ Engl J Med 2011;364:2187-98.

3. Leon MB, Smith CR, Mack MJ, et al. Transcatheter or Surgical Aortic-Valve Replacement in Intermediate-Risk Patients. N Engl J Med 2016;374:1609-20.

4. lung $B$, Laouénan $C$, Himbert $D$, et al. Predictive factors of early mortality after transcatheter aortic valve implantation: individual risk assessment using a simple score. Heart 2014;100:1016-23.

5. Capodanno D, Barbanti M, Tamburino $C$, et al. A simple risk tool (the OBSERVANT score) for prediction of 30-day mortality after transcatheter aortic valve replacement. Am J Cardiol 2014;113:1851-8.

6. Edwards FH, Cohen DJ, O'Brien SM, et al. Development and Validation of a Risk Prediction Model for In-Hospital Mortality After Transcatheter Aortic Valve Replacement. JAMA Cardiol 2016;1:46.

7. Fried LP, Tangen CM, Walston J, et al. Frailty in older adults: evidence for a phenotype. J Gerontol A Biol Sci Med Sci 2001;56:M146-M157.

8. Puls M, Sobisiak B, Bleckmann A, et al. Impact of frailty on shortand long-term morbidity and mortality after transcatheter aortic valve implantation: risk assessment by Katz Index of activities of daily living. Eurolntervention 2014;10:609-19.

9. Rodés-Cabau J, Webb JG, Cheung A, et al. Long-term outcomes after transcatheter aortic valve implantation: insights on prognostic factors and valve durability from the Canadian multicenter experience. J Am Coll Cardiol 2012;60:1864-75.

10. Cockburn J, Singh MS, Rafi NH, et al. Poor mobility predicts adverse outcome better than other frailty indices in patients undergoing transcatheter aortic valve implantation. Catheter Cardiovasc Interv 2015;86:1271-7.

11. Afilalo J, Lauck S, Kim DH, et al. Frailty in Older Adults Undergoing Aortic Valve Replacement: The FRAILTY-AVR Study. J Am Coll Cardiol 2017;70:689-700.

12. Shimura T, Yamamoto M, Kano S, et al. Impact of the Clinical Frailty Scale on Outcomes After Transcatheter Aortic Valve Replacement. Circulation 2017;135:2013-24.

13. Kleczynski $P$, Dziewierz A, Bagienski $M$, et al. Impact of frailty on mortality after transcatheter aortic valve implantation. Am Heart $J$ 2017;185:52-8.

14. Kappetein AP, Head SJ, Généreux P, et al. Updated standardized endpoint definitions for transcatheter aortic valve implantation: the Valve Academic Research Consortium-2 consensus document. Eur Heart J 2012;33:2403-18.

15. Durand E, Borz B, Godin M, et al. Performance analysis of EuroSCORE II compared to the original logistic EuroSCORE and STS scores for predicting 30-day mortality after transcatheter aortic valve replacement. Am J Cardiol 2013;111:891-7.

16. Martin GP, Sperrin M, Ludman PF, et al. Inadequacy of existing clinical prediction models for predicting mortality after transcatheter aortic valve implantation. Am Heart J 2017;184:97-105.

17. Halkin A, Steinvil A, Witberg G, et al. Mortality prediction following transcatheter aortic valve replacement: A quantitative comparison of risk scores derived from populations treated with either surgical or percutaneous aortic valve replacement. The Israeli TAVR Registry 
Risk Model Accuracy Assessment (IRRMA) study. Int J Cardiol 2016:215:227-31

18. Ludman PF. UK TAVI Steering Group and the National Institute for Cardiovascular Outcomes Research. The UK transcatheter aortic valve implantation registry; one of the suite of registries hosted by the National Institute for Cardiovascular Outcomes Research (NICOR). Heart 2012;98:1787-9.

19. Rockwood K, Song X, MacKnight C, et al. A global clinical measure of fitness and frailty in elderly people. CMAJ 2005;173:489-95.

20. Katz S, Ford AB, Moskowitz RW, et al. Studies of illness in the aged. The index of adl: A standardized measure of biological and psychosocial function. JAMA 1963;185:914.

21. Nashef SAM, Roques F, Sharples LD, et al. EuroSCORE II. European Journal of Cardio-Thoracic Surgery 2012;41:734-45.

22. Rubin DB. Multiple Imputation for Nonresponse in Surveys: John Wiley \& Sons, 1987.

23. Sterne JA, White IR, Carlin JB, et al. Multiple imputation for missing data in epidemiological and clinical research: potential and pitfalls. BMJ 2009;338:b2393.

24. von Hippel PT. 4. Regression with Missing Ys: An Improved Strategy for Analyzing Multiply Imputed Data. Sociol Methodol 2007;37:83-117.

25. Steyerberg EW, Borsboom GJ, van Houwelingen HC, et al. Validation and updating of predictive logistic regression models: a study on sample size and shrinkage. Stat Med 2004;23:2567-86.

26. Janssen KJ, Moons KG, Kalkman CJ, et al. Updating methods improved the performance of a clinical prediction model in new patients. J Clin Epidemiol 2008;61:76-86.

27. Steyerberg EW. Clinical Prediction Models. New York: Springer, 2009.

28. DeLong ER, DeLong DM, Clarke-Pearson DL. Comparing the areas under two or more correlated receiver operating characteristic curves: a nonparametric approach. Biometrics 1988;44:837.

29. R Core Team R. R: A Language and Environment for Statistical Computing. R Found: Stat. Comput, 2017.

30. Wickham H. ggplot2: elegant graphics for data analysis. New York: Springer, 2009.
31. Van BS, Groothuis-Oudshoorn K. mice: Multivariate Imputation by Chained Equations in R. J Stat Softw 2011;45:1-67 http://www. jstatsoft.org/v45/i03/.

32. Alfredsson J, Stebbins A, Brennan JM, et al. Gait Speed Predicts 30-Day Mortality After Transcatheter Aortic Valve Replacement: Results From the Society of Thoracic Surgeons/American College of Cardiology Transcatheter Valve Therapy Registry. Circulation 2016;133:1351-9.

33. Green P, Woglom AE, Genereux $P$, et al. The impact of frailty status on survival after transcatheter aortic valve replacement in older adults with severe aortic stenosis: a single-center experience. JACC Cardiovasc Interv 2012;5:974-81.

34. Okoh AK, Chauhan D, Kang N, et al. The impact of frailty status on clinical and functional outcomes after transcatheter aortic valve replacement in nonagenarians with severe aortic stenosis. Catheter Cardiovasc Interv 2017;90:1000-6.

35. Nishimura RA, Otto CM, Bonow RO, et al. 2014 AHA/ACC Guideline for the Management of Patients With Valvular Heart Disease. Circulation 2014;129:e521.

36. Green P, Arnold SV, Cohen DJ, et al. Relation of frailty to outcomes after transcatheter aortic valve replacement (from the PARTNER trial). Am J Cardiol 2015;116:264-9.

37. Arnold SV, Reynolds MR, Lei Y, et al. Predictors of poor outcomes after transcatheter aortic valve replacement: results from the PARTNER (Placement of Aortic Transcatheter Valve) trial. Circulation 2014;129:2682-90.

38. Arnold SV, Afilalo J, Spertus JA, et al. Prediction of Poor Outcome After Transcatheter Aortic Valve Replacement. J Am Coll Cardiol 2016;68:1868-77.

39. Rogers $\mathrm{T}$, Alraies MC, Moussa Pacha $\mathrm{H}$, et al. Clinical Frailty as an Outcome Predictor After Transcatheter Aortic Valve Implantation. Am $J$ Cardiol 2018;121:850-5.

40. Schoenenberger AW, Moser A, Bertschi D, et al. Improvement of Risk Prediction After Transcatheter Aortic Valve Replacement by Combining Frailty With Conventional Risk Scores. JACC Cardiovasc Interv 2018;11:395-403. 